\title{
Yoga en la India antigua
}

\author{
M. ${ }^{a}$ TeResa RomÁn LÓPEZ *
}

\begin{abstract}
RESUMEN ABSTRACT
Las orientaciones precisas de la religión hindú para desarrollar las capacidades del hombre se hallan bajo el nombre de Yoga. El yoga es un conjunto de técnicas de dominio de sí mismo y meditación, que en el hinduismo adopta distintas modalidades; se puede hablar del yoga hindú, budista, jainista, etc. En sentido más restringido, el término se refiere a una de las seis escuelas ortodoxas de la filosofía india. Asimismo, se designa con la palabra yoga toda instrucción o disciplina encaminada hacia la liberación. Existen en el hinduismo numerosas denominaciones para las diferentes sendas del yoga. Las más conocidas en Occidente son:

bhakti-yoga o «yoga de la correcta actitud religiosa"; râja-yoga o "yoga del desarrollo de la conciencia”; karma-yoga $o$ "yoga de las acciones

The precise orientations of the Hindu religion to develop men abilities are under the name of Yoga.

The yoga is a join of techniques of meditation and self-domination, in which Hinduism have different modalities; it can be talk about Hindu yoga, Buddhist yoga, janist yoga, etc...

In a more restricted way, the word refers to one of the six orthodox schools of the Indian philosophy. It's desing, as well, with the word yoga, every instruction or discipline direct to liberation.

There are so many denominations in Hinduism for the different yoga ways. The most known in Occident are bhakti-yoga or "yoga of the right religious actitude»; râja-yoga or «yoga of the conscience develop"; Karmayoga or "yoga of the correct action", jñana-yogsa or "yoga of the
\end{abstract}

* Dpto. de Filosofía y Filosofía Moral y Política. UNED. 
correctas"; jñ̂ana-yoga o "yoga del conocimiento" $y$ hatha-yoga o «yoga del poder sobre el cuerpo". La doctrina clásica sobre el yoga está recogida en los Yoga-Sûtra de Patañjali. A partir de una cierta época el sistema Yoga fue combinado eclécticamente con el sistema Sâmkhya. knowledge" and hatha-yoga or "yoga of the power on the body". The classic yoga doctrine is collect in the yoga-sûtra of Patañjali. From certain age the yoga system was eclectically combine with the Sämkhya system.

\section{ORIGENES DEL YOGA}

La India es un inmenso territorio habitado por más de novecientos millones de personas en el que alternan los altares y la miseria, la fantasía y la inmundicia; un caleidoscopio de pobreza y desnutrición, de lo sagrado y de odios extremos, opulencia y muerte; pero siempre un país lleno de encanto y de misterio (Figura 1). Y además es la tierra del yoga ${ }^{`}$.

Según Huston Smith:

«La palabra yoga proviene de la misma raíz que el verbo inglés to yoke, que tiene una doble connotación: unir y someter a un adiestramiento disciplinado. Ambas connotaciones están presentes en el sánscrito. En consecuencia, por definición general, yoga es un método de adiestramiento diseñado para llegar a una integración o unión»?

\section{Para Aurobindo:}

«Según el criterio correcto de la vida y del Yoga, toda la vida es Yoga consciente o subconscientemente. Pues con este término significamos un esfuerzo metodizado en pos de la autoperfección mediante la expresión de las potencialidades latentes en el ser y una unión del individuo humano con la Existencia universal y trascendente que vemos parcialmente expresada en el hombre y en el Cosmos" ${ }^{3}$.

Existen evidencias arqueológicas que parecen indicar que las prácticas yóguicas existían ya en el valle del Indo ${ }^{4}$ (Figura 2) antes de la llegada de

\footnotetext{
Dos son las principales escuelas del Yoga, el hatha-yoga y el râja-yoga. El hatha-yoga se ocupa sobre todo de la disciplina del cuerpo; fue formulado por Gorakshanâtha, yoguin famoso que vivió alrededor del año 1200 d.C., fundador de la secta shivaíta de los Gorakshanâthis. Por su parte el râja-yoga pone el énfasis en el control de la mente. Las obras básicas de esta escuela son entre otras, los Yoga-Sûtra de Patañjali.

2 H. SMiTH, Las religiones del mundo, Thassàlia, Barcelona, 1995, pág. 43.

3 Sri Aurobindo, Síntesis del yoga, Kier, Buenos Aires, 1972, Libro I, pág. 8.

4 «Pero el hecho más importante para nuestro estudio es el descubrimiento en MohenjoDaro, de un tipo iconográfico que puede ser considerado como la primera representación plástica
} 


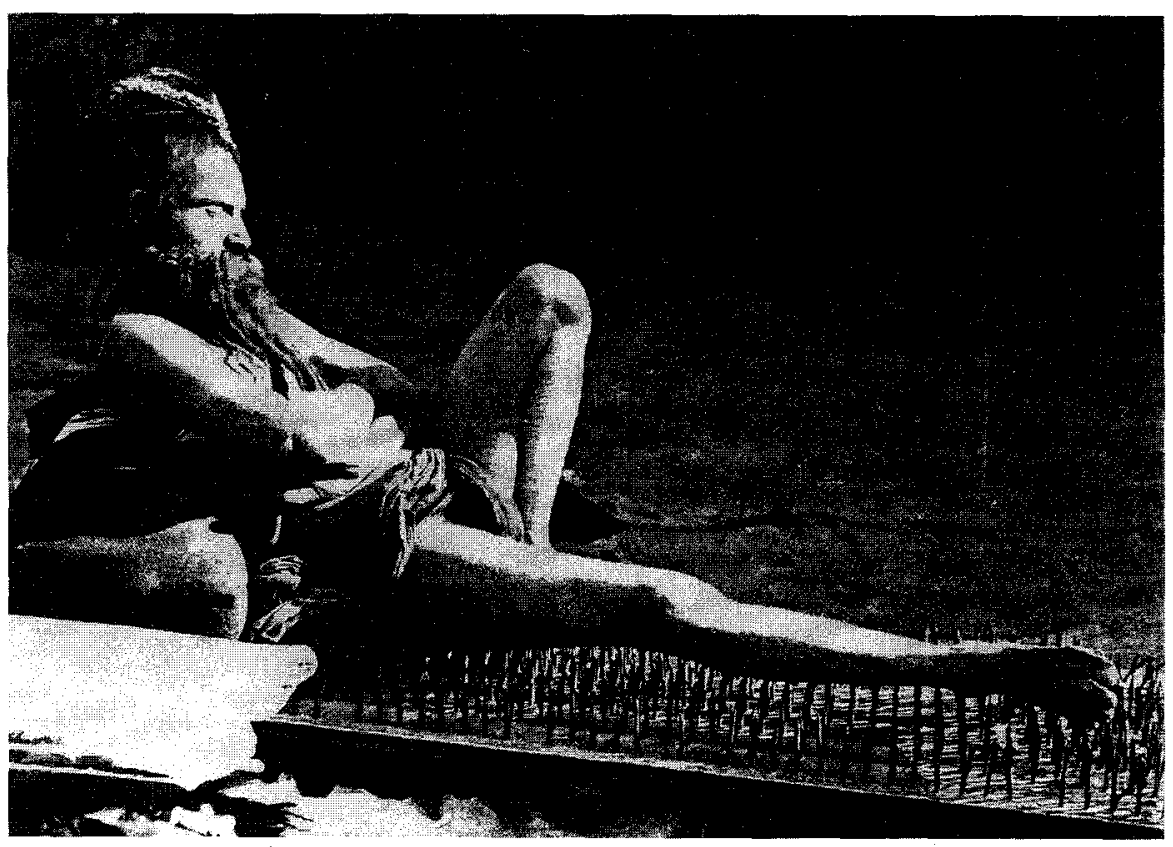

Figura 1. Faquir.

los arios ${ }^{5}$ y su cultura védica en el II milenio a.C. Sin embargo, el término yoga, en su acepción técnica, se halla por primera vez en la TaittirîyaUpanishad y en la Kâthaka-Upanishad ${ }^{6}$.

de un yogui. El mismo Gran Dios, en quien se identificara el prototipo de Siva, se encuentra allí representado en la postura específicamente yogui». M. ELIADE, Yoga, inmortalidad y libertad, La Pléyade, Buenos Aires, 1988, págs. 337-338.

5 Eran posiblemente invasores procedentes de Bactria y del norte de Irán, que se habían separado con anterioridad de las principales hordas nómadas en Rusia meridional. Su probable intervención en la desaparición de la cultura del valle del Indo viene subrayada por antiguas referencias védicas a gente hostil de tez oscura, los dasa, que vivian en las ruinas que dejaba tras de sí el dios Indra, en su encarnación de destructor de fortalezas.

6 Las Upanishad son los textos que constituyen la parte final de la Revelación védica y sientan las bases del Vedanta, las conclusiones procedentes de los Veda. Las Upanishad más antiguas fueran compuestas aproximadamente entre el 800 y el 550 a.C. Las principales Upanishad se clasifican en tres grupos: 1) Brihadâranyaka, Chândogya, Aitareya, Kaushîtaki, Kena y Taittirîya; 2) Kâthaka, îshâ, Shvetâshvatara, Mundaka y Mahânârâyana; 3) Prashna, Maitrî y Mândûkya. Además de estos tratados, hay numerosas Upanishad, de las cuales las más importantes se refieren al yoga y a las prácticas ascéticas. Véase F. Tola, Doctrinas secretas de la India Upanishads, Barrral, Barcelona, 1973, pág. 15. 


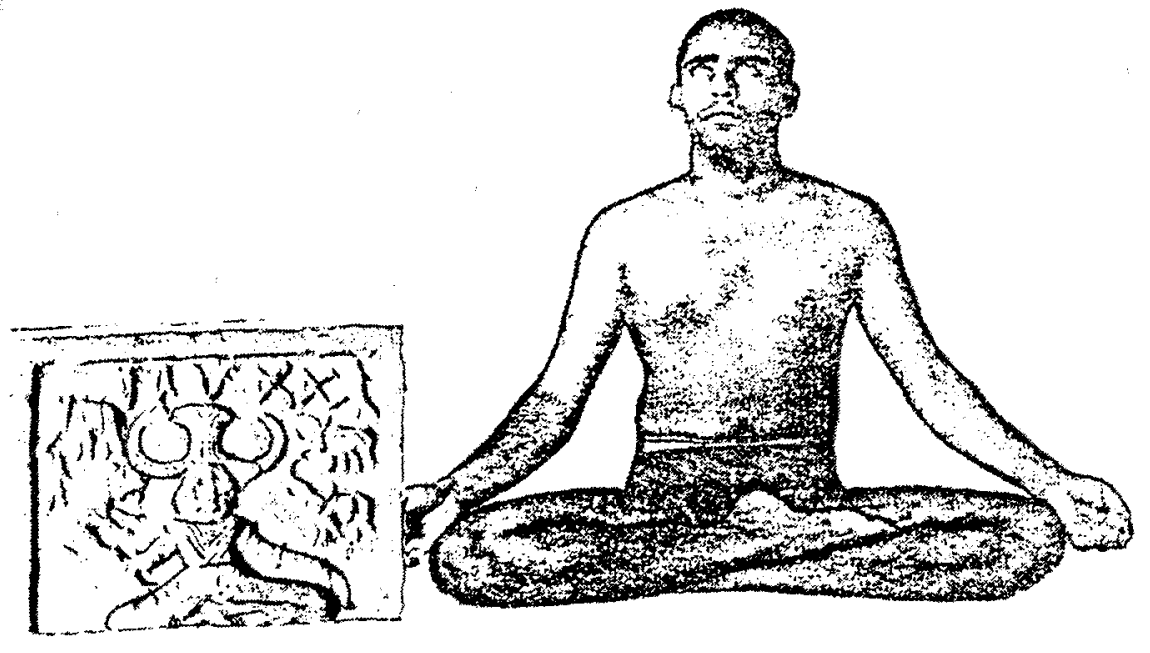

Figura 2. La práctica del yoga (derecha) puede remontarse a la civilización del Indo, como nos deja adivinar el personaje de piernas cruzadas (recuadro) de Mohenjo-daro.

«El sabio deja atrás tanto alegrías como sufrimientos y alcanza a Dios (deva) en lo más profundo de su corazón por medio de lo que se denomina adhyatma-yoga, el yoga de lo más íntimo de uno mismo. Esto es, la contemplación del Espíritu eterno, que implica la pacificación de la mente y de los sentidos. Sin embargo, paradójicamente, el Espíritu o Yo no se puede alcanzar tan sólo mediante el esfuerzo. Como afirma el Katha-Upanishad $(1,2.23)$, puede se alcanzado "sólo por aquel a quien elija". En otras palabras, aquel que reciba esta gracia. El elemento de la gracia en el proceso yóguico es enfatizado por otras muchas personas doctas en la materia, y cumple un papel primordial en el bhakti yoga; se expresa por primera vez en el Bhagavad-Gitas ?

\section{Asimismo:}

«En el Moksha-Dharma (Enseñanzas de la Liberación), en una de las secciones del decimosegundo volumen del Mahabharata, también aparecen enseñanzas yóguicas. A semejanza de las enseñanzas del Bhagavad-Gita, han sido calificadas de yoga épico o yoga preclásico, y pertenecen a varios períodos que abarcan desde el 500 a.C. hasta, tal vez, el 100 d.C. Durante dicho espacio de tiempo se compusieron muchos de los Upanishads que contienen enseñanzas yóguicas. El Shvetashvatara-Upanishad y el Maitrayaniya-Upanishad son especialmente importantes" ${ }^{8}$. 
Hacia el 200 d.C., surgió el yoga clásico. Fue codificado en los YogaSûtra o "Aforismos del Yoga» por Patañjali. Se han escrito numerosos comentarios sánscritos sobre dicho tratado. El comentario más antiguo, atribuido a Vyâsa, es el Yoga-Bhâsya.

Además del yoga clásico, florecieron otras muchas corrientes yóguicas en el período que sucedió a Patañjali. En tanto que el yoga clásico defendía una metafísica dualista (diferenciando entre materia y espíritu), casi todos los grupos yóguicos propugnaban la filosofía no dualista (advaita). Esta última es conocida como yoga posclásico ${ }^{9}$.

Las doctrinas yóguicas no dualistas se encuentran, por ejemplo en los purâna, poemas épico-devocionales que tratan leyendas sobre los dioses.

Otro importante tratado yóguico es la voluminosa literatura conocida como tantra («trama») ${ }^{10}$, perteneciente a la tradición del shaktismo (culto a Shakti).

El yoga forma parte también del shivaísmo (culto a Shiva), tal como se refleja en los âgamas (tradiciones). Asimismo, los tratados del vishnuismo (culto a Vishnú) contienen también enseñanzas yóguicas. Un notable desarrollo del yoga, que apareció bajo la influencia del tantrismo, es el hatha yoga, que dispone de su propia literatura.

Además de este importante grupo de obras sobre diversos aspectos relacionados con el yoga, existen muchos textos yóguicos en lenguas vernáculas, por ejemplo en tamil.

La historia y la literatura sobre el yoga se extienden a través de muchas tradiciones del hinduismo. En el jainismo y en el budismo pueden encontrarse también diversos enfoques yóguicos.

En el jainismo ${ }^{11}$, el término yoga, en lugar de aludir a la cesación de las facultades mentales, tal y como sucede en la obra de Patañjali, alude precisamente a la actividad psicofísica; no obstante, se señala, al mismo tiempo, la necesidad de obtener un paulatino control sobre ella. Por lo

9 En el Advaita Vedânta se ha hecho gran hincapié en las técnicas yóguicas de meditación de cara al dominio contemplativo de sí mismo y para obtener la liberación por medio del conocimiento.

10 «Los textos tántricos se presentan por lo general en la forma de un diálogo entre Shiva y Shakti. Tienen por objeto elevar a divina perfección la totalidad del ser humano enseñándole a despertar por medio de determinados ritos y prácticas de meditación la energía cósmica que lleva en su interior». M.T. RoMÁN, «Sexualidad mágica y sagrada en la India Antigua: El tantrismo», ESPACIO, TIEMPO Y FORMA, Serie II, Historia Antigua, UNED, Madrid, 1996, pág. 77.

${ }^{11}$ Movimiento religioso indio heterodoxo. Mahavira, legendario sabio de la India, es considerado el fundador del jainismo. 
demás, el sendero de la exaltación ascética, aun caracterizándose por su extremado rigor, e incluso acentuando los aspectos más propiamente éticos, es más o menos similar, si no el mismo, que en el yoga.

En lo que respecta a sus relaciones con el budismo, resultan más complejas y los puntos de vistas más diversos. L. de La Vallée Poussin sostiene que el Budismo «debe mucho a una escuela de "Yoga puro" 12. Por otra parte excluye una influencia directa del Sâmkhya-yoga (o sea, de la construcción teórica presumiblemente posterior) sobre dicho yoga budista. Asimismo el citado investigador, afirma que «por muy antiguo que pueda ser el Sâmkya-yoga, el libro de Patañjali tiene una gran deuda con el budismo» ${ }^{13}$.

En épocas modernas, distintos movimientos, incluido el de Ramakrishna, han tratado de adaptar los métodos yóguicos al mundo actual; Sri Aurobindo urgía la práctica de un «yoga integral» en que la contemplación y la autodisciplina se integran en una moral encaminada hacia los problemas de este mundo y la vida cultural.

\section{LOS YOGA-SUTTRA DE PATAÑJALI}

El Yoga es uno de los seis sistemas de filosofía hindúes ortodoxos ${ }^{14}$, es decir, de los que aceptan la autoridad védica; está muy unido al Sâmkhya ${ }^{15}$, del que tomó algunos elementos para su forma de presentar el universo, trasfondo importante y justificación al mismo tiempo de las disciplinas y métodos yóguicos. La filosofía yoga ${ }^{16}$ coincide en casi todos los aspectos con la Sâmkhya, con la excepción de que postula un Dios supremo, la única alma que escapará a los vaivenes samsáricos y la reencarnación, y que ayudará al meditador en sus esfuerzos por liberarse

12. L. de La Vallée Poussin, "Le Bouddhisme et le Yoga de Patañjali», Mélanges chinois et bouddhiques, L'Institut Belge des Hautes Études Chinoises, Bruxelles, 1937. pág. 226.

13 lbíd., ibíd.

14 Las seis darsana, puntos de vista o tradiciones filosóficas suelen aglutinarse en grupos de dos: Nyâya y Vaisesika; Sâmkhya y Yoga; por último, Mîmâmsa y Vedânta.

15 La filosofía Sâmkhya es muy antigua y su fundación se atribuye al sabio Kapila. Se trata de una doctrina atea y dualista, que reconoce básicamente dos sustancias independientes y eternas en el Universo: la prakriti, naturaleza o materia, y el purusha, espíritu o alma. La evolución de la naturaleza se explica por la variante distribución de sus tres cualidades (guna) intrínsecas: armonía, pasión e inercia. La liberación se alcanza con el conocimiento de la distinción entre purusha y prakriti, con lo que el alma se desliga de la naturaleza, se convierte en mera espectadora y no vuelve a renacer.

16 «Gracias a Patáñjali, el Yoga, de tradición «mística» que era, se convirtió en un «sistema de filosofía». M. Eliade, Patáñjali y el Yoga, Paidós, Buenos Aires, 1978, pág. 19. 
finalmente. Este último estado consiste, según el Yoga, en el aislamiento y en la eliminación del dolor.

Por otro lado, el sistema Sâmkhya señala al discernimiento (viveka) como origen de la liberación, mientras que el yoga pone el énfasis en la depuración de la conciencia por medio de distintos métodos psicofísicos con el fin de que se exprese la naturaleza oculta del alma (purusha); así, la persona llega a entender la alteridad básica del alma en conexión con los aspectos materiales y en consecuencia se libera de las cadenas de éstos ${ }^{17}$.

Los Yoga-Sûtra, que la tradición india atribuye unánimemente a Patañjali ${ }^{18}$, es el texto clásico del sistema filosófico conocido como Yoga. La citada literatura consta de cuatro libros o capítulos: el primero trata del éxtasis (samadhipâda); el segundo tiene que ver con la realización (sâdhanapâda); el tercero está dedicado a los poderes mágicos (vibhûtì); finalmente, el aislamiento (kaivalya).

No se ponen de acuerdo los distintos investigadores sobre la fecha de los Yoga-Sûtra:

«Aunque los tres primeros libros de este tratado fundamental pueden pertenecer al siglo II a.C., el cuarto es aparentemente posterior, pues contiene material que parece referirse al pensamiento budista tardío. En consecuencia, este libro, el último del tratado, ha sido atribuido al siglo $\mathrm{V}$ de nuestra era; pero la discusión aún no ha concluido. De cualquier modo, los cuatro libros de los Yoga-sûtra de Patáñjali, junto con su muy antiguo comentario (el Yoga-bhâsya, que se atribuye a Vyâsa, el legendario poeta-sabio del Mahâbhâ'rata), deben contarse entre las obras de prosa filosófica más notables del mundo" ${ }^{19}$.

Según Fernando Tola y Carmen Dragonetti:

«Los Yogasûtras son una de las obras más importantes de la cultura de la India. En parte, por su valor intrínseco como un análisis magistral del trance y como una descripción igualmente magistral del método con que se obtiene y, también, por constituir la obra básica del Yoga, sistema que tiene un papel de primerísima importancia en la cultura de la India y cuyo conocimiento es necesario para comprender las más variadas manifestaciones de esa cultu57-59.

17 Ver F. Tola y C. Dragonetti, Yoga y mística de la India, Kier, Buenos Aires, 1978, págs.

18 La opinión más generalizada en Occidente piensa que existieron dos Patañjali: uno el gramático y otro el yoguin, autor de los Yoga-sûtra, y considera que el segundo vivió entre los años 300 y 500 d.C.

${ }_{19}$ H. Zimmer, Filosofías de la India, Eudeba, Buenos Aires, 1979, pág. 227. 
ra, incluso de algunas de aquellas que rechazan la tradición ortodoxa brahmánica, como el Budismo» ${ }^{20}$.

Los Yoga-Sutra enumeran ocho anga o «miembros", que son las ocho modalidades prácticas que el meditador deberá adoptar, progresiva y sucesivamente, y que le permitirán alcanzar la concentración del espíritu y son los siguientes:

1. Yama («disciplina»), consiste en cinco preceptos morales: No matar ni herir, no robar, no mentir, no aceptar presentes y guardar continencia; deben observarse en pensamiento, palabra y obra.

2. Niyama («control»), consistente en la práctica de una serie de disciplinas psicofísicas que son: purificación interior y exterior, satisfacción, austeridad, estudio y adoración de Dios. Patañjali da los medios para practicar estas virtudes indispensables: «Si existe un impedimento debido a las inclinaciones contrarias, es preciso cultivar su opuesto» (Yoga-Sûtra, II, 33).

3. Asana («sentarse») es la postura, la posición corporal que se adopta durante los ejercicios espirituales. Ésta debe ser estable, fácil de mantener durante un tiempo prolongado, y beneficiosa. Asana designa la conocida postura que Patañjali describe como: «estable y agradable» ${ }^{21}$.

La mayor parte de los textos del hatha yoga recomiendan las siguientes asanas para la meditación: 1) Siddha-asana («postura del adepto»), se realiza presionando el talón izquierdo contra el perineo y colocando el otro pie frente a los genitales. 2) Padma-asana ("postura del loto") que se ejecuta apoyando el pie derecho en el muslo izquierdo y el pie izquierdo en el muslo derecho. 3) Sukha-asana («postura agradable») es cómoda, ya que lo más importante es que la cabeza, cuello y tronco formen una línea recta. Esto se obtiene cruzando las piernas ${ }^{22}$.

4. Prânâyâma significa control y desarrollo del aliento. La «retención» del aliento con los pulmones llenos o vacíos constituye un episodio importante de esta disciplina. Como afirma Patañjali:

«el objetivo del prânâyama es una suspensión lo más larga posible de la respiración, a lo cual se llega retardando progresivamente su ritmo» ${ }^{23}$.

\footnotetext{
20 F. Tola y C. Dragonetti, Yogasûtras de Patañjali, Barral, Barcelona, 1973, pág. 14.

21 Los tratados de hatha-yoga dan la descripción de innumerables asanas; se han llegado a numerar 8.400 .000 , de las que solamente 32 merecerían ser consideradas excelentes. En realidad, no se aprenden en un libro sino que son transmitidos por el gurú («maestro espiritual»).

22 Ver Swami Vishnudevananda, Yoga, Alianza, Madrid, 1975, págs. 85-92.
} 
Según Feuerstein:

«Es posible influir de forma consciente y hasta cierto grado en la respiración; puede modificarse e incluso detenerse completamente durante un apreciable lapso de tiempo. A finales del siglo $x i x$, un yogui conocido con el nombre de Haridas dejó desconcertado a un equipo de médicos dedicados a la investigación al permanecer durante cuarenta días encerrado en un arcón hermético» ${ }^{24}$.

En este sentido Mircea Eliade comenta lo siguiente:

«En marzo de 1829, el Asiatic Monthly Journal relataba las hazañas de un yogin que, entre otras cosas, podia permanecer varias horas bajo el agua. Se negaba a explicar cómo lo lograba, limitándose a decir que eso era en él una costumbre» 25 .

5. Prâtyâhâra («alejarse de») consiste en la retracción de los sentidos, es decir, en la adquisición de una autonomía espiritual con relación a los estímulos externos.

La finalidad del prâtyâhâra es evitar que la actividad sensorial sea acaparada por lo objetos exteriores, es decir, realizar una especie de aislamiento sensorial. El practicante, a partir de ese momento, tendrá el poder total sobre sus músculos, sus nervios y sus órganos. Podrá comenzar su gran obra con ayuda de las técnicas psicológicas de concentración, de meditación y de contemplación que le llevarán a la conquista total de su espíritu y luego a la del conocimiento trascendente.

6. Dhâranâ («contención» o «concentración») consiste en la fijación de la atención sobre un objeto cualquiera, real o ficticio, exterior o interior. Patañjali define la concentración como "la fijación de la mente en un lugar» (Yoga-Sûtra, III, 1). La actividad sensorial y el inconsciente introducen de un modo continuo en el campo de nuestra conciencia objetos, representaciones, que la invaden y dominan. La concentración sobre un solo objeto permitirá al meditador controlar progresivamente su actividad sensorial. Podría así llevar a cabo poco a poco no solamente un aislamiento sensorial sino controlar igualmente su memoria y poner en marcha energías subyacentes.

7. Cuando el practicante consigue concentrar su atención sin esfuerzo durante un largo período de tiempo, sucede, espontáneamente, una im-

\footnotetext{
M. Eliade, ob. cit., pág. 51.

G. Feuerstein, ob. cit., pág. 84.

M. EliADE, ob. cit., pág. 51.
} 
portante transformación en la conciencia. Esta nueva cualidad se denomina dhyâna («meditación»). Patañjali la define como "la continua fijeza del conocimiento sobre estos (lugares)» (Yoga-Sûtra, III, 2).

8. Samâdhi («fijación», "concentración») es el resultado último y la culminación de todos los esfuerzos y técnicas espirituales del meditador.

Cuando la mente «se absorbe» en el «objeto» en que se ha fijado, alcanza el samadhi, o fijación total del psiquismo en el objeto: "Cuando esta misma (meditación) asume como única forma la del objeto de meditación, quedando como privada de naturaleza propia, entonces se da el enstasis" (Yoga-Sûtra, III, 3).

\title{
Para Fernando Tola y Carmen Dragonetti:
}

\begin{abstract}
"En virtud del "monoideismo" que la concentración trae consigo las funciones de la mente cesan, no se dan ni ideas ni raciocinios ni sentimientos ni voliciones, ni recuerdos; los sentidos dejan de funcionar y los olores, los sabores, las formas desaparecen; el mundo externo deja de afectar al individuo, no llega a él, ha sido eliminado; uno mismo deja de percibirse, de sentirse, de vivirse: el individuo está completamente calmo, sereno, impasible, inalterable, solo frente al objeto que brilla ante él con una presencia extraordinaria. Un instante más y el mismo objeto desaparece y el individuo se sume en un estado de vaciedad y aislamiento total y absoluto» ${ }^{26}$.
\end{abstract}

En ia literatura yóguica hallamos diversas modalidades de fases de la concentración suprema: una se alcanza fijando la mente en un punto del espacio o en una idea (samâdhi «con soporte»); otra en que la mente permanece aislada, sin reparar en ningún objeto (samâdhi «sin soporte»), y que se considera superior al primero. Según Vivekananda, cuando llega a este estado supraconsciente, el practicante obtiene un conocimiento más allá del razonamiento, el conocimiento metafísico y trascendental; conoce la verdad última, y queda, pues, realmente iluminado ${ }^{27}$.

\section{TIPOS DE YOGA}

El Yoga de Patañjali constituye el yoga clásico: un conjunto de reglas prácticas y de realizaciones muy circunscritas a los principios metafísicos 
del Sâmkhya, como ya hemos visto. No obstante, existen otras formas del yoga.

El denominado mantra-yoga, es un sistema relacionado con la utilización del sonido. Según Feuerstein:

«El mantra yoga es el camino que conduce al Absoluto indiferenciado por medio del vehículo de la vibración sónica. Su objetivo es unificar la conciencia por medio de la recitación y contemplación de sonidos numinosos denominados mantras" ${ }^{28}$.

Las obras tántricas ofrecen una explicación esotérica de la palabra mantra ${ }^{29}$. Relacionan sus dos sílabas la raíz verbal man y el sufijo tra con las palabras manana («pensar») y trana ("salvar»). Así pues, el mantra es una forma de pensamiento cargada de poder que sirve como instrumento de salvación espiritual o liberación. Para el lama Anagarika Govinda:

«El mantra no puede dar poder más que a aquél que es consciente de su esencia, al que conoce sus modos de aplicación, al que sabe que es el medio idóneo de despertar a las fuerzas que duermen dentro de sí mismo, por medio de las cuales puede estar en disposición de actuar sobre su propio destino y sobre lo que le rodea" 30 .

El mantra-yoga surgió con el auge del tantrismo, hace aproximadamente dos mil años. En épocas posteriores, evolucionó un enfoque yóguico independiente que constaba de numerosos elementos rituales. Este completo sistema queda destacado en obras sánscritas como el MantraYoga-Samhitâ (Compendio de Mantra Yoga) y en el Mantra-Mahodadhi (Océano de mantras).

El râja-yoga es la forma trascendente del Yoga. Utiliza en realidad todas las formas del Yoga y se considera generalmente la meta superior de éstas. Según Ouspensky:

«El Raja-Yoga tiene en relación con el mundo psíquico del hombre, con su auto-conciencia, el mismo significado que el Hatha-Yoga tiene en relación con el mundo físico. El Hatha-Yoga es el Yoga del dominio del cuerpo, del control sobre el cuerpo y sus funciones; el Raja-Yoga es el Yoga del dominio

28 G. Feuerstein, ob. cit., pág. 108.

29 Existen veinte millones de mantras. Uno de los mantras más conocidos tanto en Occidente como en la India, es Hare Rama Hare Rama, Rama Rama Hare Hare, Hare Krishna, Krishna Krishna Hare Hare.

30 A. Govinda, Fundamentos de la mística tibetana, Eyras, Madrid, 1980, pág. 22. 
de la auto-conciencia ilusoria y falsa del hombre y del control sobre la conciencia.

EI Raja-Yoga enseña al hombre lo que constituye la base de la filosofía del mundo entero: el conocimiento de si mismo" ${ }^{31}$.

Para Vivekananda:

"La ciencia del raya yoga se propone darnos tales medios de observación de los estados internos. El instrumento requerido para ello es la mente misma. El poder de la atención, debidamente guiado, y dirigido hacia el mundo interior, analizará la mente y nos mostrará diversos hechos. Los poderes de la mente son como rayos dispersos; cuando se concentran iluminan. Este es nuestro único medio de acceder al conocimiento» ${ }^{32}$.

El yoga más conocido en occidente hoy en día es el Hatha-yoga. La palabra hatha se traduce por "vigoroso" o "fuerza» y se refiere a aquella rama del yoga que trata de obtener la autotransformación y la autotrascendencia a través de una intensa purificación física y el fortalecimiento propio.

El hatha-yoga era en su origen una disciplina del raja-yoga, tal y como lo había enseñado Patañjali, por la cual se ponían en funcionamiento los centros de energía psíquica (cakras) para hacer emerger la energía psicoespiritual (kundalini) a grados más altos de conciencia. Sus prácticas más relevantes son los asana (posturas corporales) y el prânâyâma, el dominio de las corrientes del prâna. Su principal objetivo es reunir el ha (hálito solar, denominado prêna) con el tha (hálito lunar, Ilamado apâna). Así el practicante consigue fuerzas espirituales y la Kundalini inicia su ascenso por los seis centros de energía psíquica (Figura 3).

Otro tipo de yoga es el denominado bhakti-yoga. Este yoga es esencialmente el yoga del amor y de la devoción, cristalizado en la BhagavadGîtâ como un añadido a los yogas karma y jñâna. Utiliza esencialmente las técnicas de acción sobre la conciencia basadas en el desarrollo de la afectividad, para obtener el acceso al plano superior de la conciencia. Entre ellas está la práctica de viveka (discernimiento); vimoha (no sometimiento a los deseos); abhyasa, los ejercicios espirituales, la dirección del pensamiento hacia Dios, el empleo de todas las técnicas que permiten afirmar este tropismo (música, oración), y, por encima de ellas, aninsha, la noherida.

P.D. OUSPENSKY, Un nuevo modelo del universo, Kier, Buenos Aires, 1985, pág. 273.

32

Swami Vivekananda, ob. cit., pág. 45. 


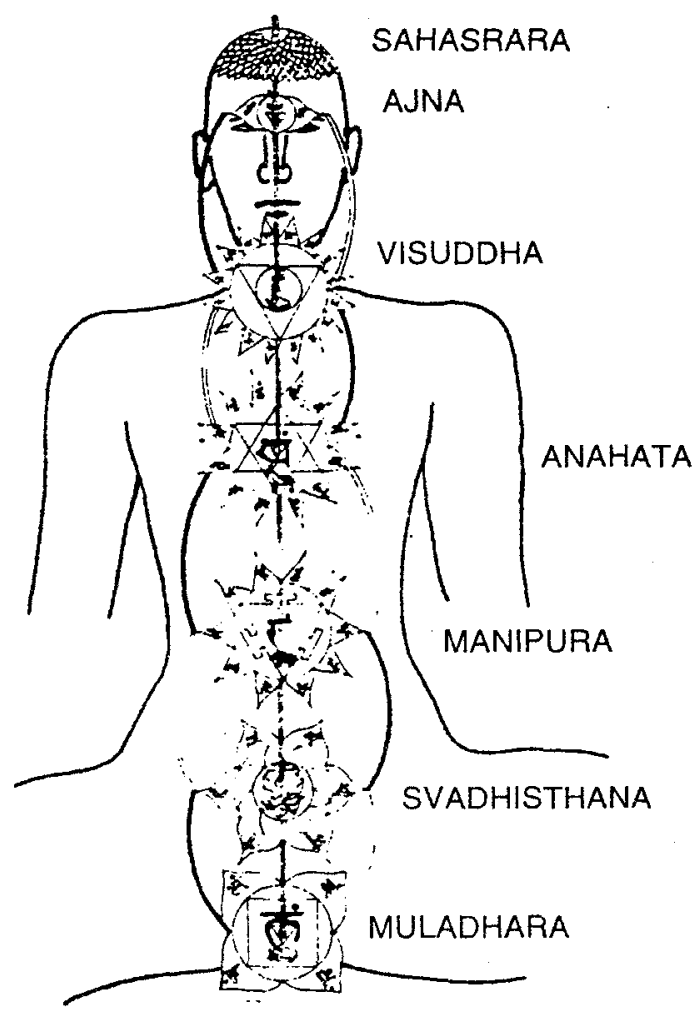

Figura 3. Los chakras.

Otra modalidad del Yoga es el llamado karma-yoga. Éste representa la vía de la acción, de utilizar la vida cotidiana, el propio oficio, o una disciplina atlética, como una forma de yoga, como la propia vía para descubrir quiénes somos.

En el karma-yoga, el practicante desarrolla métodos de trabajo en los que el único beneficio buscado es el de la influencia de la actividad sobre el psiquismo. En la Bhagavad-Gîtâ, V, 30, se lee:

"Aquél que dedica sus acciones a Brahman y las ejecuta sin apego no es manchado por el pecado, como los pétalos del loto no son tocados por el agua».

El jñâna-yoga está reservado esencialmente a los intelectuales puros. Utiliza las fuerzas del discernimiento como técnicas de acción sobre la conciencia. Estos principios fundamentales están consignados en las Upa- 
nishad. Raramente se llega al samâdhi, es decir, a la entrega, al conocimiento trascendente, solamente con el jnâna-yoga; es necesario añadir otras disciplinas yóguicas según las tendencias profundas del discípulo.

Además de los yogas mencionados, muchos otros como laya-yoga, kriyâ-yoga, nâda-yoga, siddha-yoga, tantra-yoga o kundalini-yoga, anticipan diferentes métodos para conseguir objetivos concretos.

\section{PODERES YÓGUICOS}

Patañjali se refiere, en su lista de los siddhi, a todos los «poderes»legendarios que obsesionan tanto al folclore como a la mitología y a la metafísica india. Al explicar por qué el samyama ${ }^{33}$ relativo a la forma del cuerpo puede hacer invisible al practicante, Patañjali señala que el samyama vuelve imperceptible el cuerpo al resto de los sujetos, y «como el poder de manifestación en el ojo está separado, se hace invisible el cuerpo del yogui» (Yoga-Sûtra, III, 21).

Patañjali cita asimismo los otros "prodigios» que se consiguen por el samyama, tales como conocer con exactitud el instante de la muerte (YogaSûtra, III, 23), o poderes físicos extraordinarios (Yoga-Sûtra, III, 25), o «el conocimiento de lo sutil, lo oculto, lo distante» (Yoga-Sûtra, III, 26), etc. Todo lo que es "meditado", es - por la virtud mágica de la meditaciónasimilado, poseído. Un yogui fue siempre considerado en la India como un mahâsiddha, un detentador de poderes ocultos, un hechicero, un mago.

Según Patañjali, y la tradición del Yoga clásico, el yogui utiliza los incontables «poderes» con el objetivo de recuperar la libertad última, de ninguna manera para conseguir el dominio - fragmentario y provisorio- de los elementos. Porque es la liberación y no los «poderes ocultos» la que representa al verdadero «dominio».

En general se admite que estos poderes pueden constituir un mayor obstáculo para la liberación del practicante que los apegos ordinarios a la vida: quien se arriesga por esos senderos puede llegar a convertirse en un mago más que en un yogui. Patañjali es muy claro: "Por el rechazo de estos poderes tiene lugar la destrucción de la verdadera semilla del mal, lo que conduce al kaivalya» (Yoga-Sûtra, III, 51). No obstante, sea cual sea la utilización propuesta para tales poderes, nadie en este contexto niega

33 Samyama designa las fases finales de la técnica yogui: la concentración (dhâranâ), la meditación (chyâna) y la contemplación (samâdhi). 
que acompañan el proceso normal hacia la liberación y que constituyen, por ende, su verificación.

Los relatos hindúes no han cesado de hablar de yoguis capaces, ya sea de obtener la inmortalidad o, cuando menos edades prodigiosamente prolongadas, ya de desdoblarse, de penetrar en el cuerpo de otro individuo, e incluso de reanimar los cadáveres. Asimismo, numerosos son los fenómenos telepáticos, de visión a distancia y de profecía que, en general, se ha dicho que acompañan al yoga ${ }^{34}$.

\section{Según Mircea Eliade:}

«Hacia mediados del pasado siglo, el doctor J.M. Honigberger asombró al mundo científico relatando la historia del yogin Hari-dâs. En Láhor [Lahore], en presencia del maharajá Ránjit Sing de Panjâb y de su corte, Hari-dâs se puso en estado cataléptico y fue enterrado en un jardín. Durante cuarenta días, una guardia estricta vigiló su tumba. Cuando se exhumó al yogin, estaba inconsciente, rígido y frío. Se le aplicaron toallas calientes en la cabeza, lo friccionaron, se le insufló aire por una especie de respiración artificial, y finalmente Hari-dâs volvió a la vida» ${ }^{35}$.

El Buda (Figura 4) también habla de los siddhi y la descripción que da de ellos sigue muy de cerca la tradición mágica panhindú así como la, inmemorial, de los chamanes y de los brujos «primitivos».

El monje (bhikku), recuerda el Buda:

«experimenta las variadas clases de poderes extraordinarios: Siendo uno, se torna múltiple, siendo múltiple, se torna uno; puede aparecer y desaparecer; sin encontrar resistencia va a través de las paredes, a través de las cercas, a través de las montañas, como en el aire; se hunde en la tierra o emerge de ella, como en el agua; camina sobre el agua sin que ésta se abra, como en la tierra; va a través del espacio en postura pallanka, como un pájaro alado; toca y palpa con su mano el sol y la luna, tan poderosos, tan maravillosos; hasta el mundo de Brahmà ejerce su poder con su cuerpo" ${ }^{36}$.

No obstante, para el Buddha tanto como para Patañjali, los siddhi son poderes paranormales cuya posesión no podemos eludir. A lo largo

\footnotetext{
34 Para una explicación fisiológica de la vivencia de levitación y de la variación térmica en el cuerpo como efecto del entrenamiento autógeno (que tantos puntos de contacto tiene con el Yoga), ver J.H. SCHULTZ, El entrenamiento autógeno, Científico-Médica, Barcelona, 1987, págs. 9698 y 284 respectivamente.

${ }_{35}$ M. ElIADE, ob. cit., pág. 11.

36 C. Dragonetti; Digha Nikaya, Monte Ávila, Buenos Aires, 1977, pág. 199.
} 


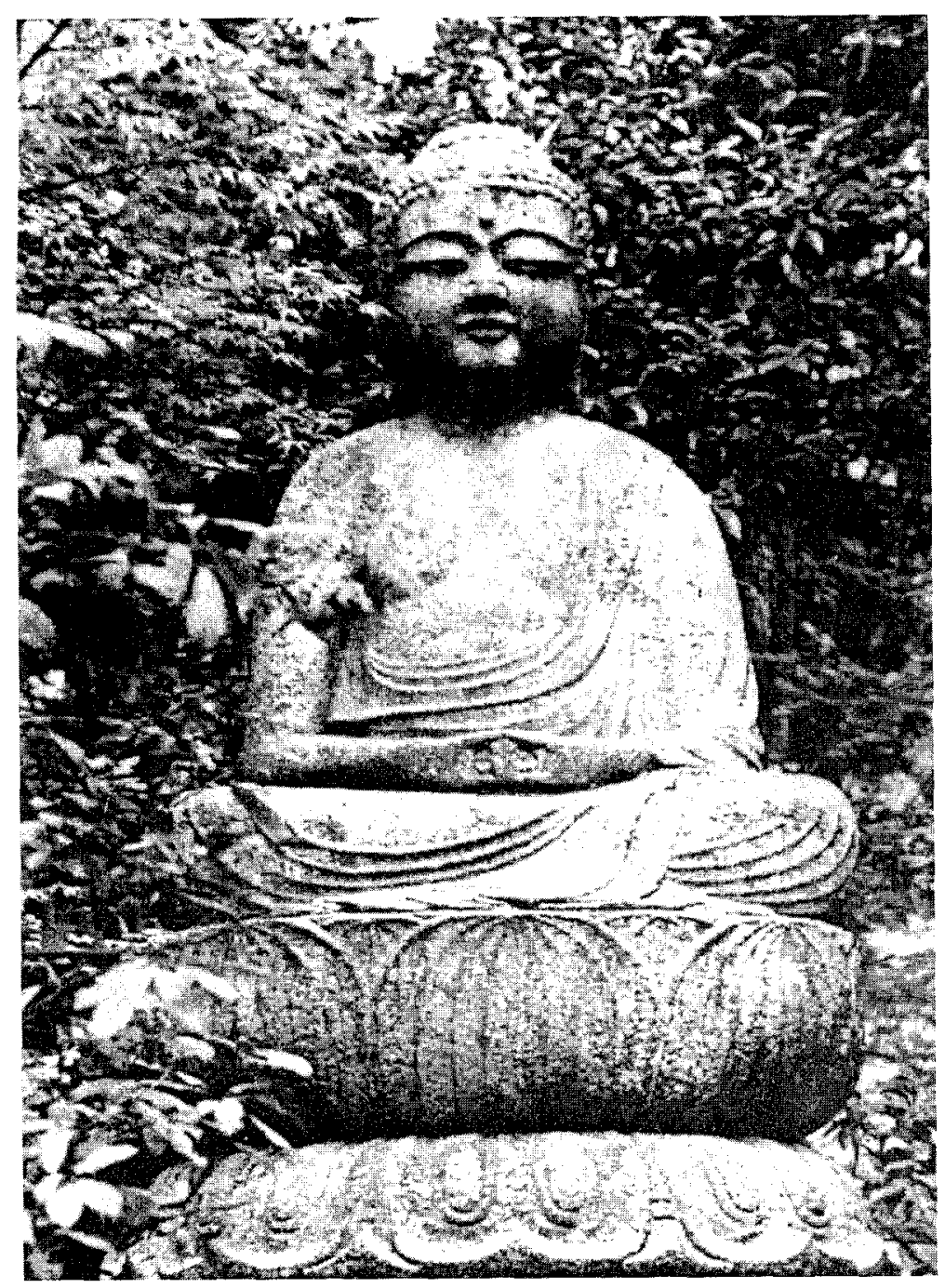

Figura 4. Estatua del Buda.

de la práctica meditativa, el bhikku (monje), desemboca necesariamente en un nivel de experiencia donde la percepción extrasensorial y el resto de los «poderes maravillosos» le son dados. El Buddha, Patañjali y otros, llaman la atención no solamente sobre el peligro de mostrar dichos poderes, sino también sobre el peligro que representa para el que los posee, 
"por cuanto el yogui está arriesgado a sucumbir a la tentacićn de la magia y de contentarse con el gozo de esos "poderes maravillosos", en lugar de proseguir su trabajo espiritual y de obtener la liberación final» ${ }^{37}$.

Por su parte el orientólogo Alain Daniélou, al referirse a los «poderes maravillosos" (siddhis), afirma que son:

«Los obstáculos más temibles que el discípulo encuentra en su itinerario hacia la reintegración» [...]. Son ocho y se manifiestan cuando se ha alcanzado un perfecto control del aliento; son los siguientes: hacerse pequeño como un átomo, volverse ingrávido, ser inmensamente grande, transportarse a cualquier parte, conseguir que se cumplan sus deseos, controlar a todas las criaturas y los elementos, disfrutar de una gloria inigualada.

Solamente ejercitándose en la concentración pueden adquirirse treinta poderes «sutiles» subsidiarios; he aquí algunos de ellos: conocimiento de los nacimientos anteriores, arte de leer los pensamientos, invisibilidad, conocimiento del Cosmos... y muchos otros. Son menos peligrosos que los anteriores.

Finalmente los poderes llamados «espirituales» son los aspectos superiores de los mismos fenómenos: conocimiento de la ilusión del espacio y del tiempo... conocimiento del hecho de ser el Sí MISMO... Por otra parte, existen 84 posturas (asanas), cada una dotada de un poder especial: destrucción de las enfermedades, paz, perfeccionamiento de los órganos sensoriales, del intelecto... Suficiente para llenar de estupefacción a los curiosos e ignorantes occidentales" ${ }^{38}$.

Para la Dra. Thérèse Brosse: «el despertar y la subida de Kundalini puede provocar la aparición de "poderes" o "siddhis", simples "accidentes en el camino", que el occidental, por desgracia, apetece golosamente" ${ }^{39}$.

Es en el curso de las diferentes etapas del samprajanata samadhi cuando el yogui adquiere ciertos poderes que Patañjali clasificó perfectamente en el capítulo III de los Yoga-Sûtra. Los budistas los Ilaman «los cinco abhijas»:

1) La clariaudiencia;

2) Los fenómenos de videncia;

3) La memoria larga;

4) La lectura del pensamiento;

5) Los poderes extraordinarios.

37 M. Eliade, Mitos, sueños y misterios, Grupo Libro 88, Madrid, 1991, pág. 92.

38 Citado en T. Brosse, Conciencia-energía, Taurus, Barcelona, 1981, págs. 134-135.

39 Ibíd., pág. 134. 
En algunas obras tántricas, especialmente en el Satcakranirupana y en el Padukapancaka, hay estudios detallados de estas percepciones extrasensoriales y la descripción de los métodos que permiten desarrollarlas.

Para Mircea Eliade:

«Parece fuera de duda que los estados catalépticos pueden ser provocados a voluntad por yogin experimentados. La doctora Thérèse Brosse ha demostrado que la reducción de la respiración y de la contracción cardíaca, hasta un punto que no se verifica de ordinario sino en los umbrales de una muerte inevitable, es un fenómeno auténticamente fisiológico que los yogin pueden llevar a cabo a fuerza de voluntad y no por efecto de una autosugestión. Claro está que un yogin tal puede ser enterrado sin riesgo alguno" ${ }^{40}$.

\section{Por su parte Ouspensky dice que:}

"Yogis» es el nombre que recibe los que viven y actúan de acuerdo con el "Yoga". Estos son hombres que pasan o han pasado por una cierta escuela y que viven de acuerdo con ciertas reglas que sólo ellos les son conocidas y que no pueden ser comprendidas por los no iniciados, y en virtud de un conocimiento que los provee de poderes infinitamente superiores a los de los hombres comunes y corrientes [...]. Estos poderes y facultades los adquieren los yoguis por los métodos y ejercicios que constituyen el secreto del Yoga y que los ponen en posibilidad de comprender a las gentes y de obrar correcta y convenientemente en todas las circunstancias y en todos los momentos de la vidas ${ }^{41}$.

\section{BIBLIOGRAFIA}

AURoBindo, Sri. (1972): Síntesis del yoga, Kier, Buenos Aires.

BernaRd, T. (1972): El camino práctico del yoga, La Pléyade, Buenos Aires.

BLAY, A. (1986): Tantra Yoga, Iberia, Barcelona.

Brosse, T. (1981): Conciencia-energía, Taurus, Madrid.

DragonetTi, C. (1977): Digha Nikaya, Monte Ávila, Buenos Aires.

ELIADE, M. (1978): Patáñjali y el yoga, Paidós, Buenos Aires.

(1988): C Yoga, inmortalidad y libertad, La Pléyade, Buenos Aires.

(1991): C Mitos, sueños y misterios, Grupo Libro 88, Madrid.

Evans-WENTZ, W.Y. (1975): Yoga tibetano y doctrinas secretas, Kier, Buenos Aires.

FEUERSTEIN, G. (1998): Yoga, Oniro, Barcelona.

GLASENAPP, H. von (1977): La filosofía de los hindúes, Barral, Barcelona.

GovindA, A. (1980): Fundamentos de la mística tibetana, Eyras, Madrid.

LA VALLÉE-POUSSIN, (1936-37): “Le Bouddhisme et le Yoga de Patañjali», en Mélanges chinois et bouddhiques, Bruxelles.

Masson-Oursel, P. (1963): Le Yoga, P.U.F., París.

40 M. ElIADE, Patáñjali y el yoga, Ed. cit., págs. 51-52.

41 P.D. OUSPENSKY, Ob. cit., pág. 260. 
MerLo, V. (1995): Experiencia yóguica y antropología filosófica, Fundación Centro Aurobindo, Barcelona.

OUSPENSKY, P.D. (1985): Un nuevo modelo del universo, Kier, Buenos Aires.

PATAÑJALI (1972): Aforismos sobre el yoga, Doncel, Madrid.

ROMÁN LÓPEZ, M.T. (1996): Diccionario de las Religiones, Alderabán, Madrid. (1997): C Buda: Sendero del alma, Aula Abierta, UNED, Madrid.

(1995): C «La magia hindú y su proyección hacia Occidente en el mundo antiguo", ESPACIO, TIEMPO Y FORMA, Serie II, Historia Antigua, UNED, Madrid, págs. 85-126.

(1996): C «Sexualidad mágica y sagrada en la India Antigua: El tantrismo". ESPACIO, TIEMPO Y FORMA, Serie II, Historia Antigua, UNED, Madrid, págs. 65-93.

SCHULTZ, J.H. (1987): El entrenamiento autógeno, Científico-Médica, Barcelona.

SivanANDA, Swami (1974): Kundalini Yoga, Kier, Buenos Aires.

SMITH, H. (1995): Las religiones del mundo, Thassàlia, Barcelona.

TOLA, F. y DRAgonetTi, C. (1973): Yogasutras de Patañjali, Barral, Barcelona.

(1973): Doctrinas secretas de la India Upanishads, Barral, Barcelona.

(1978): Yoga y mística de la India, Kier, Buenos Aires.

Tuccl, G. (1974): Historia de la filosofía hindú, Luis Miracle, Barcelona.

VISHUDEVANANDA (1975): El libro de yoga, Alianza, Madrid.

Vivekananda, Swamı (1975): Raya Yoga, Kier, Buenos Aires.

Woons, J.H. (1988): The yoga-system of «Patañjali», Motilal Banarsidass, Delhi.

ZIMMER, H. (1979): Filosofías de la India, Eudeba, Buenos Aires. 